\title{
Backyard poultry
}

\section{KEY POINTS}

- Backyard poultry are technically food producing animals

- Where medicines are prescribed under the cascade, only medicines containing substances listed in the Table of Allowed Substances should be used

- Withdrawal periods for the cascade use of medicines should take into account the withdrawal periods for the species in which the product is authorized, along with the fact that a chicken or duck's ovary contains approximately 14 egg yolks, all at various stages of development

Over the past decade, small scale poultry keeping has increased dramatically. Many of these new keepers view their poultry as pets rather than farmyard animals. However, irrespective of the purpose for which poultry are kept, they are technically 'farm animals' and 'food producing animals'. Unlike in horses, there is no current provision allowing for poultry to be classed as non-food producing animals. This has implications for medicating such birds and for their disposal after death.

\section{Poultry}

There does not appear to be a definition of poultry in the Veterinary Medicines Regulations (VMR), but there is under other UK legislation.

The Avian Influenza (Preventative Measures) (England) Regulations 2006 defines poultry as: all birds that are reared or kept in captivity for the production of meat or eggs for consumption, the production of other commercial products, for restocking supplies of game or for the purposes of any breeding programme for the production of these categories of birds.

The Diseases of Poultry (England) Order 2003 defines poultry as: domestic fowls, turkeys, geese, ducks, guinea fowls, quails, pigeons, ratites and pheasants and partridges reared or kept in captivity for breeding, the production of meat or eggs for consumption or for restocking supplies of game.

There are a great number of medicines (antimicrobials) authorized for use in poultry, all of which have meat withdrawal periods that can be easily followed. For male birds and turkeys, the use of any of these medicines is straightforward. However, for egglaying chickens or ducks, the majority of authorized products state that they 'should not be given to birds producing eggs for human consumption'.

For commercial laying flocks, products with a zero-day egg withdrawal are almost exclusively used. These products are licensed for a small number of diseases, and any birds failing to respond are humanely euthanased. For general practitioners dealing with pet chickens, such an approach would be unthinkable.

When treating backyard poultry, before any medication is prescribed under the cascade, the veterinary surgeon (veterinarian) must ensure that the ingredient(s) are listed in the Table of Allowed Substances in Commission Regulation (EU) No $37 / 2010$ (@).

\section{Defining birds as producing eggs for human consumption}

Classifying whether or not birds are producing eggs for human consumption is difficult. Prepubescent chickens are allowed to be treated with products not licensed for birds producing eggs for human consumption up to 14 days prior to the point of lay. Should a bird come into lay prior to the 14-day period elapsing, then any eggs laid within this period should not be eaten.

For owners using their eggs for hatching rather than eating, these birds are not considered to be producing eggs for human consumption. Furthermore, owners could potentially argue that they will never eat eggs from a treated bird. However, if the poultry are re-homed or sold (as frequently happens with breeding birds), their new owners may not be aware that any eggs from their new birds should not be eaten. 


\section{Antimicrobials}

The majority of antimicrobials authorized for use in poultry do not have established Maximum Residue Limits (MRLs) for eggs. Furthermore, many of these antimicrobials have explicit notes in the Table of Allowed Substances to explain that they are not to be used in birds producing eggs for human consumption.

Before the cascade use of any product, the prescribing veterinary surgeon must ensure that there is no authorized product to treat the patient's condition. For non-egg producing birds, there are a sufficient number of products available with meat withdrawal periods. For laying birds, the prescribing veterinary surgeon must then use a product under the cascade. There is no preference for using a product with an MRL for eggs versus one without an MRL.

(9) See also Antibacterials

\section{Antimicrobials with a defined MRL for eggs}

\begin{tabular}{|c|c|c|}
\hline Products with a defined MRL in eggs & MRL & Spectrum of activity \\
\hline Chlortetracycline & $200 \mu \mathrm{g} / \mathrm{kg}$ & $\begin{array}{l}\text { Mycoplasma, Salmonella, Escherichia coli, Pasteurella and } \\
\text { Clostridium perfringens }\end{array}$ \\
\hline Colistin* & $300 \mu \mathrm{g} / \mathrm{kg}$ & E. coli (poor intestinal absorption) \\
\hline Erythromycin & $150 \mu \mathrm{g} / \mathrm{kg}$ & Mycoplasma, Pasteurella and E. coli \\
\hline Lincomycin & $50 \mu \mathrm{g} / \mathrm{kg}$ & $\begin{array}{l}\text { Staphylococcus, Erysipelothrix, Mycoplasma and Clostridium } \\
\text { perfringens (poor intestinal absorption) }\end{array}$ \\
\hline Neomycin* & $500 \mu \mathrm{g} / \mathrm{kg}$ & E. coli (poor intestinal absorption) \\
\hline Oxytetracycline & $200 \mu \mathrm{g} / \mathrm{kg}$ & Mycoplasma, Salmonella, E. coli, Pasteurella and Staphylococcus \\
\hline Phenoxymethylpenicillin* & $25 \mu \mathrm{g} / \mathrm{kg}$ & Clostridium perfringens (poor intestinal absorption) \\
\hline Tiamulin* & $1000 \mu \mathrm{g} / \mathrm{kg}$ & Mycoplasma and Brachyspira \\
\hline Tylosin* & $200 \mu \mathrm{g} / \mathrm{kg}$ & Mycoplasma and Clostridium perfringens \\
\hline Tylvalosin* & $200 \mu \mathrm{g} / \mathrm{kg}$ & Mycoplasma gallisepticum and Orthinobacterium rhinotrachealae \\
\hline
\end{tabular}

*Antimicrobials currently authorized in the UK with zero-day egg withdrawal preparations available

If none of the products in this table are suitable, then the prescribing veterinary surgeon must use the cascade to prescribe either a product authorized to treat another condition in the same species or a product authorized to treat the same condition in another food producing species.

(9) See also the Prescribing cascade.

The following table details antimicrobials in the Table of Allowed Substances that have no MRLs for eggs but that do not specifically indicate that they are not to be used in birds producing eggs for human consumption. Only currently available antimicrobials in the UK have been listed.

\section{Antimicrobials allowed in food producing animals in the UK with no specific prohibition for use in birds producing eggs for human consumption}

\begin{tabular}{l} 
Products with no MRL for eggs but that do \\
not indicate 'not for use in birds producing \\
eggs for human consumption' \\
\hline Marbofloxacin \\
\hline Cefquinome* \\
\hline Ceftiofur* \\
\hline Gamithromycin \\
\hline Tulathromycin
\end{tabular}

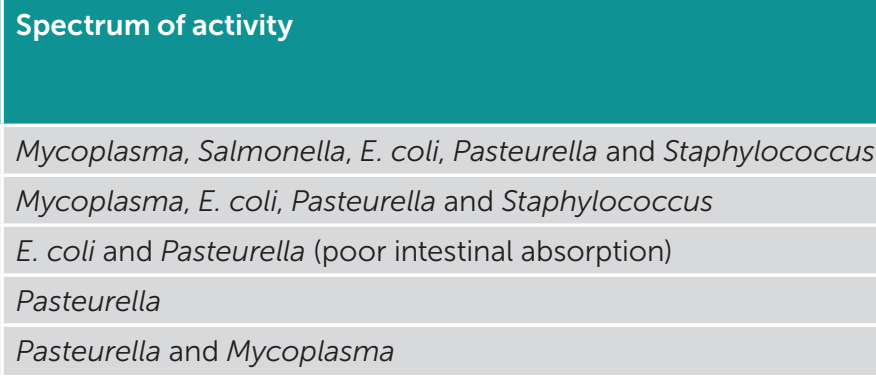

*Although these products could be technically allowed, due to the risk posed to humans from AMR, their use in poultry is contraindicated.

There are some products for which an MRL cannot be established and, therefore, must not be used in any foodproducing animals, as listed in the following table:

\section{Prohibited substances}

\begin{tabular}{l} 
Chloramphenicol \\
\hline Chlorpromazine \\
\hline Colchicine \\
\hline Dapsone \\
\hline Dimetridazole \\
\hline Metronidazole \\
\hline Nitrofurans (including furazolidone) \\
\hline Ronidazole
\end{tabular}




\section{Anticoccidials}

There are two currently authorized anticoccidial agents in the UK: toltrazuril and amprolium. Toltrazuril has no MRLs for eggs and states that it should not be used for birds producing eggs for human consumption, but is licensed in birds 4 weeks prior to the onset of lay. As coccidiosis normally affects prepubescent birds, toltrazuril can usually be used in cases of coccidiosis. Amprolium does not require an MRL and can be used in laying chickens with a zero-day egg withdrawal.

\section{Anthelmintics}

Currently, fenbendazole and flubendazole are authorized in the UK with an established MRL for eggs. There are preparations of both with zero-day egg withdrawal.

(9) See also Antiparasitic resistance.

\section{Ectoparasite treatments}

There are a number of ectoparasite treatments listed in the Table of Allowed Substances with no MRLs for eggs. Most of these do not prohibit their use in birds producing eggs for human consumption. However, it must be ensured that any treatments considered are listed in the Table of Allowed Substances, as a number of products authorized for small animals, such as fipronil, are not.

\section{Other veterinary products}

For other veterinary medicines, such as analgesics, there are no currently authorized products for poultry in the UK. Almost all such products have no MRLs for eggs, but also do not prohibit their use in birds producing eggs for human consumption.

\section{Setting an egg withdrawal period}

When setting withdrawal periods under the prescribing cascade, the minimum withdrawal period for eggs is 7 days and for meat is 28 days. However, the Veterinary Medicines Directorate (VMD) guidelines also state that consideration must be given to the withdrawal periods set for other species. For example, a meat withdrawal period may be used as a guide when setting an egg withdrawal period. Additionally, consideration must be given to avian physiology; laying hens and ducks tend to have at least 14 days' worth of eggs developing in their ovary.

In practice, the meat withdrawal period set for products used under the cascade should either be 28 days or identical to the meat withdrawal period for the authorized (food-producing) species (whichever is longer).

With regard to egg withdrawal periods, they should be a minimum of 7 days, but if there is a meat withdrawal period, this should be used as a guide, with 15 days added on to take into account the developing egg yolks.

Where a product is being used 'off-label', it is advisable to have the owner sign an informed consent form.

(9) See also Informed consent.

Note: Owners selling eggs must keep a veterinary medicines record book. Records need to be kept for at least 5 years. 


\section{QUESTIONS}

1. Which of the following best describes the status of backyard poultry as food-producing animals?

a. Poultry, when kept as pets, are not counted as food-producing animals and can, therefore, be treated as any cat or dog would

b. Poultry are classed as food-producing animals unless the owner signs a disclaimer

c. All poultry, whether pets or commercial livestock, are classed as food-producing animals

d. Poultry can be classed in the same way as horses and classified as food producing or non-food producing

2. Which one of the following statements is true?

a. Most antimicrobials have an MRL set for eggs

b. A veterinary medicine cannot be used in poultry without an MRL set for poultry meat and eggs

c. Many products that have no MRL for eggs state in their literature that they are not to be used in birds producing eggs for human consumption

d. Any antimicrobial can be used in egg-producing poultry if the owner agrees not to eat the eggs

3. A client presents a pet chicken with lice and the veterinary surgeon wants to use a spot-on treatment. What should they do next?

a. Treat the bird and advise that any eggs laid are discarded for the next 7 days

b. Check in the Table of Allowed Substances that the active ingredient in the spot-on is listed in the table

c. Treat the bird and as the medication is a spot-on, no egg withdrawal needs to be applied

d. Advise the owner that no treatment is permitted and the bird must be euthanased

4. A client presents an 8-week-old pullet with bloody droppings. Faecal oocyst counts confirm the suspicion of coccidiosis. What treatment options can be considered?
a. Toltrazuril
b. Amprolium
c. Both toltrazuril and amprolium could be used
d. Neither product

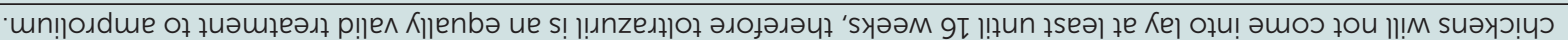

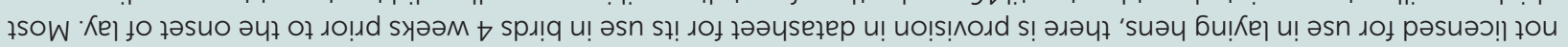

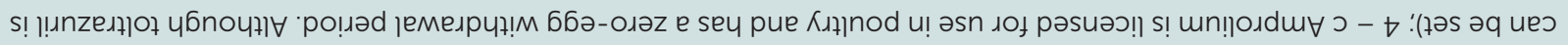

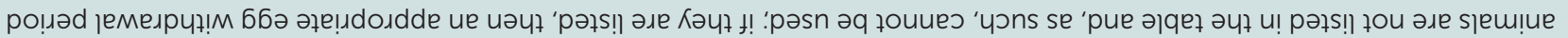

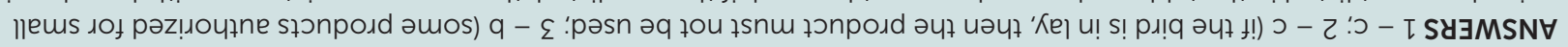

